\title{
Relationships between personality traits and attitudes toward the sense of smell
}

\section{Han-Seok Seo*, Suji Lee and Sungeun Cho}

Department of Food Science, University of Arkansas, Fayetteville, AR, USA

\section{Edited by:}

Ilona Croy, University of Gothenburg,

Sweden

\section{Reviewed by:}

Bettina Von Helversen, University of

Basel, Switzerland

Lenka Nováková, Charles University,

Czech Republic

${ }^{*}$ Correspondence:

Han-Seok Seo, Department of Food Science, University of Arkansas, 2650 North Young Avenue, Fayetteville, AR 72704, USA

e-mail: hanseok@uark.edu

\begin{abstract}
Olfactory perception appears to be linked to personality traits. This study aimed to determine whether personality traits influence human attitudes toward sense of smell. Twohundred participants' attitudes toward their senses of smell and their personality traits were measured using two self-administered questionnaires: the Importance of Olfaction Questionnaire and the Eysenck Personality Questionnaire-Revised. Demographics and olfactory function were also assessed using a self-administered questionnaire. Gender-induced differences were present in attitudes toward sense of smell. Women participants were more dependent than men participants on olfactory cues for daily decision-making. In addition, as participants evaluated their own olfactory functions more positively, they relied more on olfactory information in everyday life. To determine a relationship between personality traits and attitudes toward sense of smell, Spearman partial correlation analyses were conducted, with controlling the factors that might influence attitudes with respect to sense of smell (i.e., gender and self-awareness of olfactory function) as covariates. Participants who scored high on the lie-scale (i.e., socially desirable and faking good), tended to use olfactory cues for daily decision-making related both to social communication and product purchase. In conclusion, our findings demonstrate a significant association between personality traits and attitudes toward sense of smell.
\end{abstract}

Keywords: attitude toward sense of smell, personality traits, gender, the Eysenck Personality Questionnaire-Revised, lie-scale

\section{INTRODUCTION}

Despite its important role, relatively little attention has been paid to the sense of smell compared to other senses (e.g., vision and hearing). The sense of smell is mainly associated with eating behavior, awareness of environmental hazard, and social communication (for a review, see Stevenson, 2010). Olfactory function influences appetite (De Jong et al., 1999), food perception and palatability (Aschenbrenner et al., 2008; Seo and Hummel, 2009; Novakova etal., 2012; Schubert etal., 2012), and foodrelated social behavior (Aschenbrenner et al., 2008). For example, people with olfactory impairment appear to be more exposed to risks of unbalanced nutritional status (Duffy etal., 1995; Schiffman and Graham, 2000) and poor food intake (Aschenbrenner etal., 2008), although these findings have not been consistently observed in previous studies (De Jong et al., 1999; Schubert et al., 2012; Smoliner et al., 2013). In addition, a sense of smell can detect not only microbial risks such as feces, decay, and spoilage (Stevenson, 2010), but also non-microbial threats such as gas leaks and smoke (Miwa et al., 2001; Santos et al., 2004; Croy et al., 2012). Finally, the major histocompatibility complex (MHC) genotype and body odors can play a critical role in mate selection, not only by avoiding inbreeding, but also by detecting fit partners (Wedekind et al., 1995; Gangestad and Thornhill, 1998; Herz and Inzlicht, 2002; Croy etal., 2013; for a review, see Yamazaki and Beauchamp, 2007; Stevenson, 2010). For example, women students rated body odors of T-shirts worn by men different from themselves with respect to MHC alleles significantly more pleasant than body odors of T-shirts worn by men with similar MHC alleles (Wedekind et al., 1995). Olfactory signals can also deliver individual identity (Olsson etal., 2006; Lundström etal., 2008), emotional states (Chen and Haviland-Jones, 2000; PrehnKristensen etal., 2009; Croy etal., 2011a), age-related information (Mitro etal., 2012), and sexual interests (Croy etal., 2013). Croy et al. (2013) demonstrated an interesting relationship between sense of smell and sexual relationships in people diagnosed with isolated congenital anosmia. Men born without a sense of smell reported significantly fewer sexual relationships compared to age-matched healthy men. Also, women born without a sense of smell appeared to feel less secure about sexual partnership compared to healthy women in a control group.

Although the sense of smell plays a significant role in modulating eating behavior, hazard detection, and social communication (Stevenson, 2010), people's attitudes toward sense of smell vary as a function of olfactory performance (Frasnelli and Hummel, 2005; Shu etal., 2011), gender (Frasnelli and Hummel, 2005; Ferdenzi et al., 2008; Havlicek et al., 2008; Croy et al., 2010; Seo et al., 2011), and culture (Schleidt et al., 1981; Schaal et al., 1997; Ferdenzi et al., 2008; Seo et al., 2011). For example, patients with olfactory impairments tend to complain more strongly about their decreased quality of life than people with normal olfactory function (Frasnelli and Hummel, 2005). Furthermore, women patients consider olfactory impairment-decreased 
quality of life more negatively than do men patients (Frasnelli and Hummel, 2005). Gender-induced difference in attitudes toward olfaction is also observed in people with a normal sense of smell (Ferdenzi etal., 2008; Havlicek etal., 2008; Croy et al., 2010). It seems that women are more attentive than men to olfactory cues (Ferdenzi et al., 2008; Havlicek et al., 2008; Croy et al., 2010; Seo et al., 2011).

Personality is another potential factor in modulating olfactory perception (Koelega, 1970, 1994; Filsinger et al., 1987; Pause et al., 1998; Larsson et al., 2000; Chen and Dalton, 2005; Havlíček et al., 2012; La Buissonnière-Ariza et al., 2013). Earlier research demonstrated plausible relationships between olfactory sensitivity and personality traits such as extraversion/introversion; the results, however, are controversial. Koelega (1970) reported that olfactory sensitivity was positively correlated with degree of extraversion but not with degree of neuroticism. In contrast, another study by Herberner etal. (1989) demonstrated that, in comparison to extremely sociable participants, extremely shy participants were significantly more sensitive to odors. Furthermore, several studies reported no significant relationship between olfactory sensitivity and extraversion/introversion (Filsinger et al., 1987; Koelega, 1994; Pause et al., 1998; Larsson et al., 2000; Havlíček etal., 2012). Pause et al. (1998) found that neuroticism, when compared to extraversion, has a stronger impact in determination of olfactory sensitivity. Havlíček et al. (2012) also reported that olfactory sensitivity correlated with neuroticism, but not with other personality traits such as extraversion, openness, and agreeability (but see also Croy et al., 2011b). In addition, personality traits may alter a participant's ability to identify odors (Larsson et al., 2000; Havlíček et al., 2012). For example, participants who scored high in neuroticism (i.e., more emotional and anxious) identified odors more correctly (Larsson et al., 2000). In contrast, participants with high degrees of impulsiveness and assertiveness identified odors less correctly (Larsson et al., 2000). A recent study conducted by Havlíček et al. (2012) found a significant correlation between participants' anxiety traits (a neuroticism facet) and their ability to discriminate odors. That is, as participants were more anxious, they discriminated odors more correctly. Finally, personality modulates participants' reaction speed with respect to olfactory cues (Chen and Dalton, 2005). Chen and Dalton (2005) demonstrated that both neurotic and anxious men detected pleasant/unpleasant odors more quickly than emotionally neutral odors, while stable and calm men detected both odors equally quickly (i.e., no significant differences in reaction time to both pleasant/unpleasant and neutral odors). In a more recent study, La Buissonnière-Ariza et al. (2013) compared response times of both high- and low-trait anxiety adults to pleasant- and unpleasant-smelling food odors (i.e., strawberry and fish odors, respectively). Similarly to previous findings of Chen and Dalton (2005), they found that, regardless of whether odors were pleasant or unpleasant, highly anxious individuals detected odors more quickly than did less anxious ones.

Likewise, earlier studies have highlighted the modulatory effects of personality traits on olfactory perceptions such as odor sensitivity, discrimination, and identification. In addition, previous research has demonstrated that people's attitudes toward sense of smell can vary as a function of olfactory performance
(Frasnelli and Hummel, 2005; Shu et al., 2011). Given the two ideas that (1) personality traits influence olfactory performance and (2) olfactory performance appears to be closely related to attitudes toward olfaction, we hypothesized that personality traits could be related to attitudes toward sense of smell. Up to now, little has been known about a potential connection between personality traits and attitudes toward sense of smell. To build on previous findings, this study has aimed to determine whether human attitudes toward sense of smell can be related to personality traits.

\section{MATERIALS AND METHODS}

This study was conducted in conformance with the Declaration of Helsinki for studies on human subjects. The protocol was approved by the University Institutional Review Board of the University of Arkansas (Fayetteville, AR, USA).

\section{PARTICIPANTS}

A total number of 207 volunteers (73 men and 134 women) representing an age range of 18-73 years [mean age \pm standard deviation $(\mathrm{SD})=39 \pm 14$ years] took part in this study. Data from seven volunteers (four men and three women) who had either clinical histories of major diseases (e.g., diabetes and cancer) or olfactory impairment were discarded. The olfactory impairment was determined based on results obtained through a "Sniffin' Sticks" screening test (Burghart Instruments, Wedel, Germany; for details, see Hummel et al., 2001). Accordingly, data from a total of 200 respondents ( 69 men and 131 women) were analyzed. Table 1 shows the demographic details of the respondents. The experimental procedure was thoroughly explained to all participants and a written informed consent was obtained from each prior to participation.

\section{QUESTIONNAIRES}

Participants' attitudes toward sense of smell, personality traits, and their demographics and self-ratings with respect to olfactory function were measured using self-administered questionnaires.

\section{Attitudes toward sense of smell}

To assess participants' attitudes toward sense of smell, we used the "Importance of Olfaction Questionnaire" (IOQ) designed by Croy et al. (2010). The IOQ includes three subscales: "association," "application," and "consequence." Each subscale is in turn composed of six questions to be answered with a 4-point category scale ( $1=$ I totally disagree to $4=$ I totally agree). The associationsubscale indicates emotion, memory, and episode triggered by a sense of smell. The application-subscale reflects the extent to which people use sense of smell in their daily activities. Finally, the consequence-subscale reflects the extent to which people rely on sense of smell for daily decision-making. The additional subscale of "aggravation" developed for clinical applications (Croy et al., 2010) was not used because this study was designed for a general population.

\section{Personality}

Participants' personality traits were assessed using the "Eysenck Personality Questionnaire-Revised” (EPQ-R; Eysenck et al., 1985). The EPQ-R, a 48-question self-reporting questionnaire, examines four major dimensions of personality trait: "psychoticism" 
Table 1 | Participants' demographic profiles and self-ratings of olfactory function.

\begin{tabular}{|c|c|c|c|}
\hline \multirow[b]{2}{*}{ Categories } & \multirow[b]{2}{*}{ Subcategories } & \multicolumn{2}{|c|}{$(N=200)$} \\
\hline & & Frequency & $\%$ \\
\hline \multirow[t]{2}{*}{ Gender } & Men & 69 & 34.5 \\
\hline & Women & 131 & 65.5 \\
\hline \multirow[t]{4}{*}{ Age group } & $18-24$ years & 27 & 13.5 \\
\hline & $25-44$ years & 107 & 53.5 \\
\hline & $45-64$ years & 59 & 29.5 \\
\hline & 65 years and over & 7 & 3.5 \\
\hline \multirow[t]{4}{*}{ Body mass index } & Underweight (less than 18.5) & 6 & 3.0 \\
\hline & Normal weight (18.5-24.9) & 77 & 38.5 \\
\hline & Overweight (25.0-29.9) & 46 & 23.0 \\
\hline & Obese (more than 30.0 ) & 70 & 35.0 \\
\hline Ethnicity & Caucasian & 193 & 96.5 \\
\hline \multirow[t]{2}{*}{ background } & African-American & 1 & 0.5 \\
\hline & Asian & 6 & 3.0 \\
\hline Annual household & Under $\$ 15,000$ & 29 & 14.5 \\
\hline \multirow[t]{5}{*}{ income } & $\$ 15,000$ to $\$ 34,999$ & 46 & 23.0 \\
\hline & $\$ 35,000$ to $\$ 54,999$ & 36 & 18.0 \\
\hline & $\$ 55,000$ to $\$ 74,999$ & 31 & 15.5 \\
\hline & $\$ 75,000$ to $\$ 94,999$ & 27 & 13.5 \\
\hline & More than $\$ 95,000$ & 31 & 15.5 \\
\hline \multirow[t]{4}{*}{ Education level } & High school & 62 & 31.0 \\
\hline & 2-year college & 28 & 14.0 \\
\hline & 4-year college & 62 & 31.0 \\
\hline & Graduate school & 48 & 24.0 \\
\hline \multirow{5}{*}{$\begin{array}{l}\text { Self-ratings of } \\
\text { olfactory function }\end{array}$} & Very bad & 2 & 1.0 \\
\hline & Bad & 0 & 0.0 \\
\hline & Moderate & 15 & 7.5 \\
\hline & Good & 106 & 53.0 \\
\hline & Very good & 77 & 38.5 \\
\hline
\end{tabular}

(P: 12 questions), "extraversion" (E: 12 questions), "neuroticism" (N: 12 questions), and "lie-scale" (L: 12 questions). The psychoticism-subscale assesses behavior patterns used to characterize psychotic individuals or psychoses (Eysenck, 1997; Weiner and Craighead, 2010). The extraversion-subscale measures the extent to which individuals are sociable and active (Eysenck, 1997; Weiner and Craighead, 2010). The neuroticism-subscale assesses the extent to which individuals are predisposed to experience negative emotion (Eysenck, 1997; Weiner and Craighead, 2010). Finally, the lie-scale subscale reflects individuals' socially conforming behaviors or their tendency to "fake good" (Weiner and Craighead, 2010).

\section{Demographics and self-ratings of olfactory function}

Participants' demographics, such as gender, age, height, weight, ethnic background, annual household income, and education level, were assessed through a self-administered questionnaire.
Table 1 shows the participants' demographic profiles. In addition, participants were asked to evaluate their own olfactory functions on a 5-point Likert scale ranging from 1 (very bad) to 5 (very good).

\section{DATA ANALYSIS}

Data analysis was conducted using SPSS 21.0 for Windows ${ }^{\mathrm{TM}}$ (IBM SPSS Inc., Chicago, IL, USA). Not all participants answered all questions (i.e., several participants did not complete all subscales; one for the association-subscale, two for the consequencesubscale, and two for the lie-scale subscale). Because the ShapiroWilk test (Shapiro and Wilk, 1965) revealed that the IOQ and the EPQ-R data were not normally distributed (Table 2), non-parametric statistical methods were used for data analysis. Mann-Whitney and Kruskal-Wallis tests were used to determine whether participants' attitudes toward sense of smell varied as a function of demographic variables like gender, age, body mass index, annual household income, and education level. Spearman correlation coefficients were used to determine whether attitudes toward sense of smell were related to self-ratings of olfactory function. A relationship between participants' personality traits and their attitudes toward sense of smell can be mediated by other factors that may possibly influence attitudes toward sense of smell, i.e., demographics and self-ratings of olfactory function (Croy et al., 2010; Seo et al., 2011). Therefore, to determine whether there is a relationship between personality traits and attitudes toward sense of smell, we used partial Spearman correlation analyses with treating potential factors to affect attitudes toward sense of smell as covariates. Calculating multiple correlations between personality traits and attitudes toward sense of smell can increase the risk of a type I error. That is, multiple correlation tests increase the probability of erroneously rejecting even one of the true null hypotheses (i.e., correlation coefficient is 0 ) when there is no significant correlation (Benjamini and Hochberg, 1995; Curtin and Schulz, 1998; Benjamini and Yekutieli, 2001). To avoid the risk of multiple correlation tests, the level of statistical significance of correlation coefficients was adjusted using Bonferroni's correction (Curtin and Schulz, 1998). To keep the overall level of significance at $5 \%$ in this study, the level of significance for each correlation was divided by 12 (i.e., 4 dimensions of the EPQ-R by 3 subscales of the IOQ); the adjusted level of significance was set at $P<0.0042$.

\section{RESULTS}

Table 2 presents the results of descriptive analysis for personality traits (EPQ-R) and attitudes toward sense of smell (IOQ). As previously mentioned, the data of the IOQ and the EPQ-R were not normally distributed (Table 2), so non-parametric statistical methods were used for data analysis. Before examining the relationship between participants' personality traits and their attitudes toward sense of smell, potential factors that might possibly mediate the relationship, i.e., demographics and self-ratings of olfactory function, were determined.

\section{INFLUENCES OF DEMOGRAPHICS ON ATTITUDES TOWARD SENSE OF SMELL}

Mann-Whitney $U$-tests revealed that women participants used olfactory cues for daily decision-making more often than men 
Table 2 | Descriptive analysis results for ratings of personality traits and attitudes toward sense of smell.

\begin{tabular}{|c|c|c|c|c|c|c|}
\hline & Mean & Median & Standard deviation & Skewness & Kurtosis & $\begin{array}{l}\qquad\left(N=200^{A}\right) \\
\text { Normality of data }^{B}\end{array}$ \\
\hline \multicolumn{7}{|c|}{ Attitudes toward sense of smell $\mathrm{C}$} \\
\hline Association & 19.0 & 19.0 & 2.4 & -0.5 & 0.5 & $W=0.97(P<0.001)$ \\
\hline Application & 17.6 & 18.0 & 2.9 & -0.3 & 0.0 & $W=0.98(P=0.012)$ \\
\hline Consequence & 17.4 & 18.0 & 2.6 & -0.4 & 0.4 & $W=0.98(P=0.001)$ \\
\hline Psychoticism & 1.8 & 2.0 & 1.5 & 1.0 & 2.4 & $W=0.89(P<0.001)$ \\
\hline Extraversion & 8.0 & 9.0 & 3.6 & -0.6 & -0.8 & $W=0.90(P<0.001)$ \\
\hline Neuroticism & 4.5 & 4.5 & 3.2 & 0.3 & -1.0 & $W=0.95(P<0.001)$ \\
\hline Lie-scale & 4.7 & 4.0 & 2.6 & 0.3 & -0.7 & $W=0.95(P<0.001)$ \\
\hline
\end{tabular}

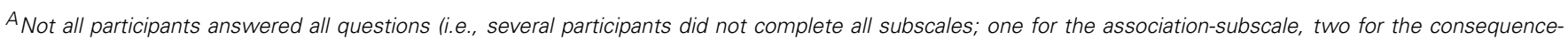
subscale, and two for the lie-scale subscale).

B Normality of data was determined by Shapiro-Wilk test (Shapiro and Wilk, 1965).

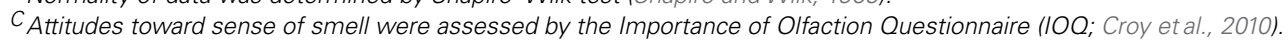

D Personality traits were assessed by the Eysenck Personality Questionnaire-Revised (EPQ-R; Eysenck etal., 1985).

participants $(P<0.001)$, as shown in Figure 1. However, there was no significant gender-induced difference in the ratings of association-subscale $(P=0.15)$ and application-subscale $(P=0.23)$.

The Kruskal-Wallis tests found that the ratings of three subscales (i.e., "association," "application," and "consequence") in the IOQ were not significantly different as a function of age groups $(P>0.05)$, body mass index $(P>0.05)$, education level $(P>0.05)$, and annual household income $(P>0.05)$.

\section{RELATIONSHIPS BETWEEN SELF-RATINGS OF OLFACTORY FUNCTION AND ATTITUDES TOWARD A SENSE OF SMELL}

Spearman correlation analyses showed that participants' selfratings of olfactory function were positively correlated with the

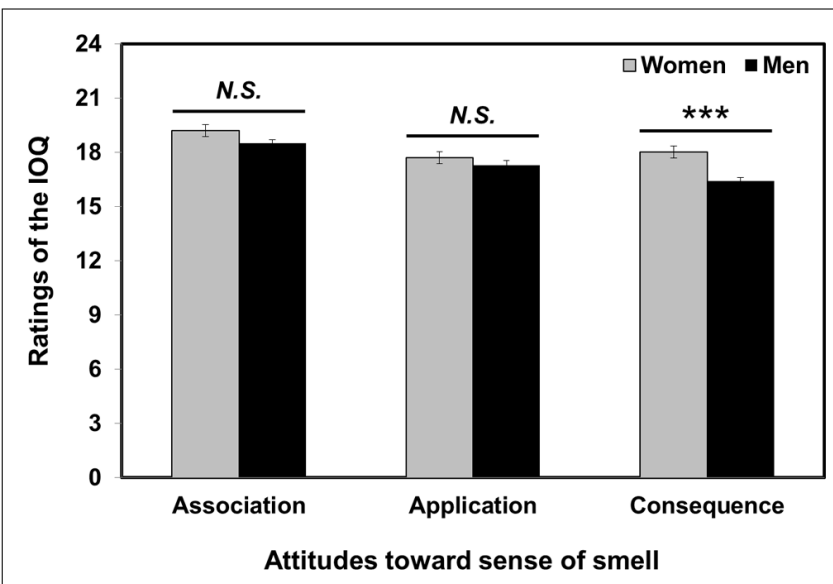

FIGURE 1 | Gender differences in the attitudes toward sense of smell. Mann-Whitney $U$-tests revealed that women participants rated consequence-subscale of the IOQ (Importance of Olfaction Questionnaire) significantly higher than men participants. The asterisks $\left({ }^{* *}\right)$ indicate significance at $P<0.001$. Error bars represent standard error of the means. ratings of application-subscale $\left(\rho_{200}=0.17, P=0.02\right)$ and consequence-subscale $\left(\rho_{198}=0.15, P=0.03\right)$. For example, when participants judged their olfactory function to be more positive, they more frequently used their sense of smell in everyday life and for daily decision-making. Additionally, the self-ratings of olfactory function showed a marginally significant correlation with the ratings of association-subscale $\left(\rho_{199}=0.14, P=0.05\right)$.

\section{RELATIONSHIPS BETWEEN PERSONALITY TRAITS AND ATTITUDES TOWARD A SENSE OF SMELL}

As previously mentioned, we controlled potential factors that might mediate the relationship between personality traits and attitudes toward sense of smell. Based on these above results, participants' gender and self-ratings of olfactory function were controlled in determining the relationship between their personality traits and attitudes toward sense of smell.

Table 3 shows partial Spearman's correlation coefficients $(\rho)$ for the relationships between personality traits and attitudes toward a sense of smell. The ratings of consequence-subscale of the IOQ significantly correlated with the lie-scale scores at the Bonferroni-adjusted level of significance $\left(\rho_{191}=0.21\right.$, $P=0.0038)$. In other words, as participants showed socially conforming behaviors (e.g., fake good), they were more dependent on olfactory cues for daily decision-making.

However, no other significant relationships among individual ratings of the IOQ and the EPQ-R were found at the Bonferroni-adjusted level of significance $(P>0.0042)$.

\section{DISCUSSION}

\section{INFLUENCES OF DEMOGRAPHICS ON THE ATTITUDES TOWARD A} SENSE OF SMELL

The current study shows gender-induced differences in attitudes toward sense of smell; compared to men, women participants reported that they use olfactory cues more often for daily decisionmaking. Although the gender difference was not apparent in all 
Table 3 | Partial Spearman correlation coefficients for the relationships between personality traits and attitudes toward sense of smell ${ }^{\text {A }}$.

$(N=200)$

\begin{tabular}{|c|c|c|c|c|}
\hline & & \multicolumn{3}{|c|}{ Attitudes toward sense of smell ${ }^{B}$} \\
\hline \multirow[t]{4}{*}{ Personality traits ${ }^{C}$} & Psychoticism & $\rho_{191}=-0.06^{N . S .}$ & $\rho_{191}=-0.01^{\text {N.S. }}$ & $\rho_{191}=-0.001^{\text {N.S. }}$. \\
\hline & Extraversion & $\rho_{191}=0.10^{N . S .}$ & $\rho_{191}=0.05^{\text {N.S. }}$ & $\rho_{191}=-0.08^{\text {N.S. }}$ \\
\hline & Neuroticism & $\rho_{191}=0.11^{\text {N.S. }}$ & $\rho_{191}=-0.01^{\text {N.S. }}$ & $\rho_{191}=0.03^{\text {N.S. }}$ \\
\hline & Lie-scale & $\rho_{191}=-0.02^{\text {N.S. }}$ & $\rho_{191}=0.09^{\text {N.S. }}$ & $\rho_{191}=0.21^{*}$ \\
\hline
\end{tabular}

A When determining correlation between a dimension of the EPQ- $R$ and a subscale of the 100 , participants' gender and self-ratings of olfactory function were treated as covariates.

${ }^{B}$ Attitudes toward sense of smell were assessed by the Importance of Olfaction Questionnaire (IOQ; Croy et al., 2010).

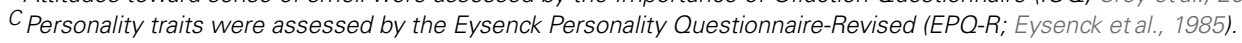

The level of significance for each correlation coefficient was adjusted using Bonferroni's correction (Curtin and Schulz, 1998).

The N.S. indicates no significance at $P<0.0042$.

The asterisk $(*)$ indicates significance at $P<0.0042$.

three subscales, our results are in agreement with earlier studies using the IOQ (Croy et al., 2010; Seo et al., 2011). Similarly, Croy et al. (2010) reported that the gender difference was obtained in the consequence-subscale, but not in the association- and application-subscales. More recently, Seo et al. (2011) reported that more women than men in four different regions: Mexico, Germany, Czech, and Korea, have attentive and positive attitudes toward sense of smell. For mate selection, men usually consider women's visual appearance most important, while women tend to evaluate men's body odors in determining superiority (Herz and Inzlicht, 2002; Havlicek et al., 2008). There are three possible explanations for gender-related differences in attitudes toward sense of smell. First, women's superior olfactory performance (e.g., odor sensitivity, discrimination, identification; Doty et al., 1984; Hummel etal., 2007) may lead them to be more attentive and reactive to olfactory cues (Croy et al., 2010). Second, the proxemics theory of Hall (1966) might account for gender-induced attitudes toward sense of smell. Hall (1963) argued that people can establish interpersonal distances in eight different dimensions, including olfactory code. Generally, women stay closer to each other (i.e., smaller interpersonal distance) than men, which may provide them with more chances for judging other peoples' body odors, identities, and emotional states (Seo et al., 2011). Finally, it should be noted that women participants in this study tended to be more neurotic and emotional than men participants (MannWhitney $U$-tests, $P<0.001)$. Considering the significant influence of neuroticism not only on olfactory performance, but also on attitudes toward sense of smell, women's higher scores in neuroticism might result in more attentive attitudes to olfactory cues. However, because no significant correlation was found between ratings of neuroticism and the consequence-subscale exhibiting gender differences, further study should be conducted to support this assertion.

\section{RELATIONSHIPS BETWEEN SELF-RATINGS OF OLFACTORY FUNCTION AND ATTITUDES TOWARD SENSE OF SMELL}

In this study, participants who judged their olfactory function more positively relied on olfactory cues in daily decision-making.
These results are consistent with previous findings demonstrating a positive correlation between self-rating of olfactory sensitivity and general attitudes toward sense of smell (Seo et al., 2011). Self-assessment of olfactory function seems to be related to selfrating of nasal patency (Landis et al., 2003) or odor annoyance (Knaapila et al., 2008) rather than to olfactory perceptions such as odor sensitivity and discrimination (Landis et al., 2003). This result reflects the fact that individuals regarding their olfactory function more positively tend to be more attentive and reactive to the sense of smell regardless of olfactory sensitivity.

\section{RELATIONSHIPS BETWEEN PERSONALITY TRAITS AND ATTITUDES TOWARD SENSE OF SMELL}

The above results demonstrate that gender and self-ratings of olfactory function may be associated with attitudes toward sense of smell. Therefore, factors such as gender and self-ratings of olfactory function were controlled as covariates when determining relationships between personality traits and attitudes toward sense of smell.

Previous research has focused on the idea that personality traits influence olfactory perceptions such as odor sensitivity (Koelega, 1970, 1994; Filsinger et al., 1987; Pause et al., 1998; Larsson et al., 2000; Croy et al., 2011b; Havlíček et al., 2012), odor intensity (Chen and Dalton, 2005), odor discrimination (Havlíček et al., 2012), odor identification (Larsson et al., 2000), and odor reaction time (Chen and Dalton, 2005; La Buissonnière-Ariza et al., 2013). Specifically, as people are more neurotic and anxious, they show better performance in detection (Pause et al., 1998; Chen and Dalton, 2005; Havlíček et al., 2012; La Buissonnière-Ariza et al., 2013), discrimination (Havlíček et al., 2012), and identification (Larsson et al., 2000) of olfactory cues. Based on previous research, it was expected that participants who scoring high in neuroticism (i.e., more anxious and emotional) would be prone to have more memory, episode, and emotion triggered by olfactory cues. According to Eysenck's (1967) hypothesis, it is assumed that individuals high in neuroticism are more sensitive to emotional cues, especially aversive and negative stimuli, and this may be related to greater activation of the limbic system. Spearman correlation 
analysis showed that the scores of neuroticism-subscale significantly correlated with ratings of association-subscale of the IOQ at $P<0.05$, but the significant relationship was not obtained at the Bonferroni-adjusted level of significance used in this study $(P<0.0042)$.

The lie-scale of the EPQ-R was designed to measure the tendency of respondents to lie or to fake effectively, thereby reflecting their acquiescence or conformity to social rules and pressures (Powell, 1977; Francis and Pearson, 1983). Interestingly, the current study demonstrated that participants scoring high in the lie-scale also showed high ratings in the consequence-subscale of the IOQ. In other words, individuals more constrained by social desirability (e.g., faking good) appear to rely more on olfactory cues when making daily-life decisions. A number of studies have elucidated that sense of smell is closely related to social communication and behavior (Wedekind et al., 1995; Gangestad and Thornhill, 1998; Chen and Haviland-Jones, 2000; Herz and Inzlicht, 2002; Olsson et al., 2006; Yamazaki and Beauchamp, 2007; Lundström et al., 2008; Prehn-Kristensen et al., 2009; Stevenson, 2010; Croy et al., 2011a, 2013; Mitro et al., 2012). Olfactory cues such as body odors reflect emotional state (Prehn-Kristensen et al., 2009; Croy et al., 2011a), individual identity (Olsson et al., 2006; Lundström etal., 2008), and sexual interests (Wedekind et al., 1995; Gangestad and Thornhill, 1998; Herz and Inzlicht, 2002; Croy et al., 2013; for review, see Yamazaki and Beauchamp, 2007; Stevenson, 2010). Olsson et al. (2006) asked participants to sniff the contents of five zip-lock bags containing both T-shirts worn by themselves, their friends, two strangers of opposite sex, and unworn T-shirts. They were then asked to identify the two shirts worn by themselves and their friends. Participants were able to determine not only their own T-shirts (51.6\%), but also the T-shirts worn by their friends (38.7\%). In addition, it is known that many people have the ability to recognize others' emotional states such as happiness, fear, and anxiety (Chen and Haviland-Jones, 2000; Prehn-Kristensen et al., 2009) by smelling their body odors. A functional brain-imaging study demonstrated that body odors related to anxiety (produced during academic examination), in contrast to control group body odors (produced during bicycling), activated brain areas associated with the processing of social-anxiety information (e.g., fusiform gyrus) and the regulation of empathic feelings (e.g., insula, cingulate cortex, and precuneus). These findings reflect the fact that olfactory signals can play a key role in social communication in our society. Accordingly, it is thought that individuals more constrained by social desirability (i.e., high scores in lie-scale of the EPQ-R) tend to pay more attention to their own body odors, the better to provide positive and favorable impressions to others. In addition, they appear to judge other people's identities, emotions, and personalities based on their body odors. In a similar vein, Croy et al. (2011b) demonstrated that agreeable participants, who tend to have greater concern for social harmony and cooperative nature (Rothmann and Coetzer, 2003), have higher sensitivities to odors. Furthermore, several studies have found that individuals with social deficits (e.g., autism and schizophrenia) have lower olfactory performances in areas like odor sensitivity (Dudova et al., 2011) and odor identification (Malaspina and Coleman, 2003). These findings support possible associations of social desirability (herein, lie-scale) not with only olfactory perceptions, but also with attitudes toward olfaction.

A plausible explanation for the relationship between smelling behavior and personality traits, especially social desirability, can be found in a neuroanatomical convergence of olfactory and emotional information in the limbic system, orbitofrontal cortex, insula, and anterior cingulate cortex (for a review, see Soudry et al., 2011). Functional brain-imaging studies have revealed that the limbic and paralimbic areas are involved in regulation of emotional and social desirability (Haas et al., 2010; Boehme et al., 2013) as well as in the processing of odor valence, odor memory, and odor-induced emotion (for review, see Gottfried, 2006; Soudry et al., 2011). Based on neuroanatomical convergence, it is to be expected that individuals who are faking good are vulnerable to emotional olfactory signals, possibly leading them to rely on olfactory cues for social communication and daily decision-making.

Since this research is a questionnaire-based study, a phenomenon known as the "extreme response style" (Hamilton, 1968; Greenleaf, 1992) should be noted. In other words, in questionnaire-based studies, regardless of specific item content, up to $30 \%$ of respondents are likely to consistently favor extreme response categories (Eid and Rauber, 2000; Austin et al., 2006; Naemi et al., 2009). Previous studies demonstrated that women and younger respondents tend to prefer extreme response categories compared to men and older respondents (Austin et al., 2006). In addition, respondents who scored high on extraversion and conscientiousness are likely to show a preference for extreme response categories (Austin etal., 2006). Because an extreme response style might result in a correlation between the ratings, the outcomes must be carefully interpreted. As seen in Table 2, both ratings of the EPQ-R and IOQ were highly skewed and, due to their non-normal distributions, non-parametric statistical methods were employed in this study, which might reduce the plausible overestimation caused by an extreme response style.

In summary, our findings provide empirical evidence that personality traits are related to attitudes toward sense of smell. Specifically, people constrained by social desirability (e.g., fake good) relied more on a sense of smell for daily decision-making. These findings provide better understanding of how personality traits are related to peoples' attitudes toward sense of smell.

\section{ACKNOWLEDGMENT}

This research was supported by start-up funding from the University of Arkansas Division of Agriculture to Han-Seok Seo.

\section{REFERENCES}

Aschenbrenner, K., Hummel, C., Teszmer, K., Krone, F., Ishimaru, T., Seo, H. S., et al. (2008). The influence of olfactory less on dietary behaviors. Laryngoscope 118, 135-144. doi: 10.1097/MLG.0b013e318155a4b9

Austin, E. J., Deary, I. J., and Egan, V. (2006). Individual differences in response scale use: mixed Rasch modeling of responses to NEO-FFI items. Pers. Individ. Differ. 40, 1235-1245. doi: 10.1016/j.paid.2005.10.018

Benjamini, Y., and Hochberg, Y. (1995). Controlling the false discovery rate: a practical and powerful approach to multiple testing. J. R. Stat. Soc. Ser. B Stat. Methodol. 57, 289-300. doi:10.2307/2346101 
Benjamini, Y., and Yekutieli, D. (2001). The control of the false discovery rate in multiple testing under dependency. Ann. Stat. 29, 1165-1188. doi:10.1214/aos/1013699998

Boehme, S., Ritter, V., Tefikow, S., Stangier, U., Strauss, B., Miltner, W. H., et al. (2013). Brain activation during anticipatory anxiety in social anxiety disorder. Soc. Cogn. Affect. Neurosci. doi: 10.1093/scan/nst129 [Epub ahead of print].

Chen, D., and Dalton, P. (2005). The effect of emotion and personality on olfactory perception. Chem. Senses 30, 345-351. doi: 10.1093/chemse/bji029

Chen, D., and Haviland-Jones, J. (2000). Human olfactory communication of emotion. Percept. Mot. Skills 91, 771-781. doi: 10.2466/pms.2000.91.3.771

Croy, I., Bojanowski, V., and Hummel, T. (2013). Men without a sense of smell exhibit a strongly reduced number of sexual relationships, women exhibit reduced partnership security - a reanalysis of previously published data. Biol. Psychol. 92, 292-294. doi: 10.1016/j.biopsycho.2012.11.008

Croy, I., Buschhüter, D., Seo, H. S., Negoias, S., and Hummel, T. (2010). Individual significance of olfaction: development of a questionnaire. Eur. Arch. Otorhinolaryngol. 267, 67-71. doi: 10.1007/s00405-009-1054-0

Croy, I., Negoias, S., Novakova, L., Landis, B. N., and Hummel, T. (2012). Learning about the functions of the olfactory system from people without a sense of smell. PLoS ONE 7:e33365. doi: 10.1371/journal.pone.0033365

Croy, I., Olgun, S., and Joraschky, P. (2011a). Basic emotions elicited by odors and pictures. Emotion 11, 1331-1335. doi: 10.1037/a0024437

Croy, I., Springborn, M., Lötsch, J., Johnston, A. N., and Hummel, T. (2011b). Agreeable smellers and sensitivity neurotics - correlations among personality traits and sensory thresholds. PLOS ONE 6:e18701. doi: 10.1371/journal.pone. 0018701

Curtin, F., and Schulz, P. (1998). Multiple correlations and Bonferroni's correction. Biol. Psychiatry 44, 775-777. doi: 10.1016/S0006-3223(98)00043-2

De Jong, N., Mulder, I., de Graaf, C., and van Staveren, W. A. (1999). Impaired sensory functioning in elders: the relation with its potential determinants and nutritional intake. J. Gerontol. A Biol. Sci. Med. Sci. 54, B324-B331. doi: 10.1093/gerona/54.8.B324

Doty, R. L., Shaman, P., Applebaum, S. L., Giberson, R., Siksorski, L., and Rosenberg, L. (1984). Smell identification ability: changes with age. Science 226, 1441-1443. doi: 10.1126/science.6505700

Dudova, I., Vodicka, J., Havlovicova, M., Sedlacek, Z., Urbanek, T., and Hrdlicka, M. (2011). Odor detection threshold, but not odor identification, is impaired in children with autism. Eur. Child. Adolesc. Psychiatry 20, 333-340. doi: 10.1007/s00787-011-0177-1

Duffy, V. B., Backstrant, J. R., and Ferris, A. M. (1995). Olfactory dysfunction and related nutritional risk in free-living, elderly women. J. Am. Diet. Assoc. 95, 879-884. doi: 10.1016/S0002-8223(95)00244-8

Eid, M., and Rauber, M. (2000). Detecting measurement invariance in organizational surveys. Eur. J. Psychol. Assess. 16, 20-30. doi: 10.1027//1015-5759.16.1.20

Eysenck, H. J. (1967). The Biological Basis of Personality. Springfield, IL: Thomas Publisher.

Eysenck, H. J. (1997). Dimensions of Personality. New Brunswick, NJ: Transaction Publishers.

Eysenck, S. B. G., Eysenck, H. J., and Barrett, P. (1985). A revised version of the psychoticism scale. Pers. Individ. Differ. 6, 21-29. doi: 10.1016/01918869(85)90026-1

Ferdenzi, C., Mustonen, S., Tuorila, H., and Schaal, B. (2008). Children's awareness and uses of odor cues in everyday life: a Finland-France comparison. Chemosens. Percept. 1, 190-198. doi: 10.1007/s12078-008-90206

Filsinger, E. K., Fabes, R. A., and Hughston, G. (1987). Introversion-extraversion and dimensions of olfactory perception. Percept. Mot. Skills 64, 695-699. doi: 10.2466/pms.1987.64.3.695

Francis, L. J., and Pearson, P. R. (1983). Are religious children bigger liars? Psychol. Rep. 52, 551-554. doi: 10.2466/pr0.1983.52.2.551

Frasnelli, J., and Hummel, T. (2005). Olfactory dysfunction and daily life. Eur. Arch. Otorhinolaryngol. 262, 231-235. doi: 10.1007/s00405-004-0796-y

Gangestad, S. W., and Thornhill, R. (1998). Menstrual cycle variation in women's preference for the scent of symmetrical men. Proc. Biol. Sci. 265, 927-933. doi: 10.1098/rspb.1998.0380

Gottfried, J. A. (2006). "Smell: central nervous processing," in Taste and Smell: An Update, eds T. Hummel and A. Welge-Lüssen (Basel: Karger), 44-69.

Greenleaf, E. A. (1992). Measuring extreme response style. Public Opin. Q. 56, 328-351. doi: 10.1086/269326
Haas, B. W., Hoeft, F., Searcy, Y. M., Mills, D., Bellugi, U., and Reiss, A. (2010). Individual differences in social behavior predict amygdala response to fearful facial expressions in Williams syndrome. Neuropsychologia 48, 1283-1288. doi: 10.1016/j.neuropsychologia.2009.12.030

Hall, E. T. (1963). A system for the notation of proxemics behavior. Am. Anthropol. 65, 1003-1026. doi: 10.1525/aa.1963.65.5.02a00020

Hall, E. T. (1966). The Hidden Dimension. New York: Doubleday.

Hamilton, D. L. (1968). Personality attributes associated with extreme response style. Psychol. Bull. 69, 192-203. doi: 10.1037/h0025606

Havlíček, J., Nováková, L., Vondrová, M., Kuběna, A. A., Valentová, J., and Roberts, S. C. (2012). Olfactory perception is positively linked to anxiety in young adults. Perception 41, 1246-1261. doi: 10.1068/p7244

Havlicek, J., Saxton, T. K., Roberts, S. C., Jozifkova, E., Lhota, S., Valentova, J., et al. (2008). He sees, she smells? Male and female reports of sensory reliance in mate choice and non-mate choice contexts. Pers. Individ. Differ. 45, 565-570. doi: 10.1016/j.paid.2008.06.019

Herberner, E. S., Kagan, J., and Cohen, M. (1989). Shyness and olfactory threshold. Pers. Individ. Differ. 10, 1159-1163. doi: 10.1016/0191-8869(89)90079-2

Herz, R. S., and Inzlicht, M. (2002). Sex differences in response to physical and social factors involved in human mate selection: the importance of smell for women. Evol. Hum. Behav. 23, 359-364. doi: 10.1016/S1090-5138(02)00095-8

Hummel, T., Kobal, G., Gudiziol, H., and Mackay-Sim, A. (2007). Normative data for the "Sniffin' Sticks" including tests of odor identification, odor discrimination, and olfactory thresholds: an upgrade based on a group of more than 3,000 subjects. Eur. Arch. Otorhinolaryngol. 264, 237-243. doi 10.1007/s00405-006-0173-0

Hummel, T., Konnerth, O. G., Rosenheim, K., and Kobal, G. (2001). Screening of olfactory function with a four-minute odor identification test: reliability, normative data, and investigations in patients with olfactory loss. Ann. Otol. Rhinol. Laryngol. 110, 976-981.

Knaapila, A., Tuorila, H., Kyvik, K. O., Wright, M. J., Keskitalo, K., Hansen, J., et al. (2008). Self-ratings of olfactory function reflect odor annoyance rather than olfactory acuity. Laryngoscope 118, 2212-2217. doi: 10.1097/MLG.0b013e3181826e43 Koelega, H. S. (1970). Extraversion, sex, arousal and olfactory sensitivity. Acta Psychol. (Amst.) 34, 51-66. doi: 10.1016/0001-6918(70)90004-1

Koelega, H. S. (1994). Sex differences in olfactory sensitivity and the problem of the generality of smell acuity. Percept. Mot. Skills 78, 203-213. doi: 10.2466/pms.1994.78.1.203

La Buissonnière-Ariza, V., Lepore, F., Kojok, K. M., and Frasnelli, J. (2013). Increased odor detection speed in highly anxious healthy adults. Chem. Senses 38, 577-584. doi: 10.1093/chemse/bjt028

Landis, B. N., Hummel, T., Hugentobler, M., Giger, R., and Lacroix, J. S. (2003). Ratings of overall olfactory function. Chem. Senses 28, 691-694. doi: 10.1093/chemse/bjg061

Larsson, M., Finkel, D., and Pedersen, N. L. (2000). Odor identification: influences of age, gender, cognition, and personality. J. Gerontol. B. Psychol. Sci. Soc. Sci. 55, 304-310. doi: 10.1093/geronb/55.5.P304

Lundström, J. N., Boyle, J. A., Zatorre, R. J., and Jones-Gotman, M. (2008). Functional neuronal processing of body odors differs from that of similar common odors. Cereb. Cortex 18, 1466-1474. doi: 10.1093/cercor/bhm178

Malaspina, D., and Coleman, E. (2003). Olfaction and social drive in schizophrenia. Arch. Gen. Psychiatry 60, 578-584. doi: 10.1001/archpsyc.60.6.578

Mitro, S., Gordon, A. R., Olsson, M. J., and Lundström, J. N. (2012). The smell of age: perception and discrimination of body odors of different ages. PLoS ONE 7:e38110. doi: 10.1371/journal.pone.0038110

Miwa, T., Furukawa, M., Tsukatani, T., Constanzo, R. M., DiNardo, L. J., and Reiter, E. R. (2001). Impact of olfactory impairment on quality of life and disability. Arch. Otolaryngol. Head Neck Surg. 127, 497-503. doi: 10.1001/archotol.127. 5.497

Naemi, B. D., Beal, D. J., and Payne, S. C. (2009). Personality predictors of extreme response style. J. Pers. 77, 261-286. doi: 10.1111/j.1467-6494.2008.00545

Novakova, L., Bojanowski, V., Havlíček, J., and Croy, I. (2012). Differential patterns of food appreciation during consumption of a simple food in congenitally anosmic individuals: an explorative study. PLOS ONE 7:e33921. doi: 10.1371/journal.pone.0033921

Olsson, S. B., Barnard, J., and Turri, L. (2006). Olfaction and identification of unrelated individuals: examination of the mysteries of human odor recognition. J. Chem. Ecol. 32, 1635-1645. doi: 10.1007/s10886-006-9098-8 
Pause, B. M., Ferstl, R., and Fehm-Wolfsdorf, G. (1998). Personality and olfactory sensitivity. J. Res. Person. 32, 510-518. doi: 10.1006/jrpe. 1998.2228

Powell, G. E. (1977). Psychoticism and social deviancy in children. Adv. Behav. Res. Ther. 1, 27-56. doi: 10.1016/0146-6402(77)90003-0

Prehn-Kristensen, A., Wiesner, C., Bergmann, T. O., Wolff, S., Jansen, O., Mehdorn, H. M., et al. (2009). Induction of empathy by the smell of anxiety. PLoS ONE 4:e5987. doi: 10.1371/journal.pone.0005987

Rothmann, S., and Coetzer, E. P. (2003). The big five personality dimensions and job performance. J. Ind. Psychol. 29, 68-74. doi: 10.4102/sajip.v29i1.88

Santos, D. V., Reiter, E. R., DiNardo, L. J., and Costanzo, R. M. (2004). Hazardous events associated with impaired olfactory function. Arch. Otolaryngol. Head Neck Surg. 130, 317-319. doi: 10.1001/archotol.130.3.317

Schaal, B., Soussignan, R., Marlier, L., Kontar, F., Karima, I. S., and Tremblay, R. E. (1997). Variability and invariants in early odour preferences: comparative data from children belonging to three cultures. Chem. Senses 22, 212.

Schiffman, S. S., and Graham, B. G. (2000). Taste and smell perception affect appetite and immunity in the elderly. Eur. J. Clin. Nutr. 54, S54-S63. doi: 10.1038/sj.ejcn.1601026

Schleidt, M., Hold, B., and Attili, G. (1981). A cross-cultural study on the attitude towards personal odors. J. Chem. Ecol. 7, 19-31. doi: 10.1007/BF00988632

Schubert, C. R., Cruickshanks, K. J., Fischer, M. E., Huang, G. H., Klein, B. E., Klein, R., et al. (2012). Olfactory impairment in an adult population: the Beaver Dam Offspring Study. Chem. Senses 37, 325-334. doi: 10.1093/chemse/bjr102

Seo, H. S., Guarneros, M., Hudson, R., Distel, H., Min, B. C., Kang, J. K., et al. (2011). Attitudes toward olfaction: a cross-regional study. Chem. Senses 36, 177-187. doi: 10.1093/chemse/bjq112

Seo, H. S., and Hummel, T. (2009). Effects of olfactory dysfunction on sensory evaluation and preparation of foods. Appetite 53, 314-321. doi: 10.1016/j.appet.2009.07.010

Shapiro, S. S., and Wilk, M. B. (1965). An analysis of variance test for normality (complete samples). Biometrika 52, 591-611.

Shu, C. H., Lee, P. O., Lan, M. Y., and Lee, Y. L. (2011). Factors affecting the impact of olfactory loss on the quality of life and emotional coping ability. Rhinology 49, $337-341$.
Smoliner, C., Fischedick, A., Sieber, C. C., and Wirth, R. (2013). Olfactory function and malnutrition in geriatric patients. J. Gerontol. A Biol. Sci. Med. Sci. 68, 1582-1588. doi: 10.1093/gerona/glt085

Soudry, Y., Lemogne, C., Malinvaud, D., Consoli, S.-M., and Bonfils, P. (2011). Olfactory system and emotion: common substances. Eur. Ann. Otorhinolaryngol. Head Neck Dis. 128, 18-23. doi: 10.1016/j.anorl.2010. 09.007

Stevenson, R. J. (2010). An initial evaluation of the function of human olfaction. Chem. Senses 35, 3-20. doi: 10.1093/chemse/bjp083

Wedekind, C., Seebeck, T., Betterns, F., and Paepke, A. J. (1995) MHC-dependent mate preferences in humans. Proc. Biol. Sci. 260, 245-249. doi: 10.1098/rspb.1995.0087

Weiner, I. B., and Craighead, W. E. (2010). The Corsini Encyclopedia of Psychology, Vol. 2. Hoboken, NJ: Wiley \& Sons, Inc.

Yamazaki, K., and Beauchamp, G. K. (2007). Genetic basis for MHCdependent mate choice. Adv. Genet. 59, 126-145. doi: 10.1016/S0065-2660(07) 59005-X

Conflict of Interest Statement: The authors declare that the research was conducted in the absence of any commercial or financial relationships that could be construed as a potential conflict of interest.

Received: 22 September 2013; accepted: 14 November 2013; published online: 28 November 2013.

Citation: Seo HS, Lee S and Cho S (2013) Relationships between personality traits and attitudes toward the sense of smell. Front. Psychol. 4:901. doi: 10.3389/fpsyg.2013. 00901

This article was submitted to Cognitive Science, a section of the journal Frontiers in Psychology.

Copyright (C) 2013 Seo, Lee and Cho. This is an open-access article distributed under the terms of the Creative Commons Attribution License (CC BY). The use, distribution or reproduction in other forums is permitted, provided the original author(s) or licensor are credited and that the original publication in this journal is cited, in accordance with accepted academic practice. No use, distribution or reproduction is permitted which does not comply with these terms. 